\title{
Predictors of event-free survival after percutaneous mitral commissurotomy
}

\author{
N Meneveau, F Schiele, M-F Seronde, V Breton, S Gupta, Y Bernard, J-P Bassand
}

\begin{abstract}
Objective-To assess the long term functional result after percutaneous mitral commissurotomy and identify the predictors of event-free survival following 10 years of experience.

Design-Analysis of clinical, echocardiographic, and haemodynamic variables at baseline and after the procedure by univariate and multivariate analyses (Cox model).

Setting-University hospital.

Patients-532 consecutive patients receiving percutaneous mitral commissurotomy in the same institution.
\end{abstract}

Results-The mean (SD) follow up was 3.8 (4.0) years. Survival at 3, 5, and 7.5 years was $94 \%, 91 \%$, and $83 \%$, respectively; event-free survival was $84 \%, 74 \%$, and $52 \%$.

Mitral valve anatomy was identified as the strongest independent predictor of eventfree survival. Age, cardiothoracic ratio, mean pulmonary artery pressure, and mean echocardiographic mitral gradient after commissurotomy were also found to be independent predictors of long term functional result. Event-free survival was $92 \%, 84 \%$, and $70 \%$ at 3,5 , and 7.5 years in patients with favourable anatomy (echo score $=1), 86 \%, 73 \%$, and $34 \%$ in patients with intermediate anatomy (echo score $=2)$, and $45 \%, 25 \%$, and $16 \%$ in patients with unfavourable anatomy (echo score $=3$ ). In patients aged $\leqslant 65$ years, the event-free survival rate was $80 \%, 70 \%$, and $45 \%$ at 3,5 , and 7.5 years $v 52 \%, 38 \%$, and $17 \%$ in patients aged $>65$ years.

Conclusions-The anatomical form of the mitral valve and the patient's age were the most powerful predictors of event-free survival. Patients with intermediate or unfavourable anatomy and those aged $>65$ years have low 5 and 7.5 year event-free survival rates. This must be taken into account when discussing the indications for percutaneous mitral commissurotomy; immediate mitral valve replacement is a reasonable alternative to balloon mitral commissurotomy in patients with higher risk of functional deterioration after the procedure.

(Heart 1998;80:359-364)

Keywords: valvoplasty; mitral valve stenosis

Since percutaneous balloon mitral commissurotomy was first introduced by Inoue et al in $1984,{ }^{1}$ it has been widely used in the treatment of mitral stenosis. Several studies have reported immediate, ${ }^{2-9}$ short term, ${ }^{10-12}$ and mid-term ${ }^{13-15}$ results of mitral commissurotomy, and its ability to improve the functional class of the patient as a result of an increase in mitral valve area. ${ }^{16}$ Clinical trials have also compared the immediate results of balloon mitral commissurotomy with surgical closed chest mitral commissurotomy and have suggested that balloon mitral commissurotomy is a suitable alternative to surgery in patients with mitral stenosis and suitable valve anatomy. ${ }^{17-19}$ It has been shown that the predictive factors for a good immediate result after mitral commissurotomy depend directly on the baseline mitral valve anatomy, which is the basis of a precommissurotomy scoring system. ${ }^{20-23}$ To date, several reports on mid- and long term outcome after balloon mitral commissurotomy and associated predictive factors have been published, ${ }^{24-34}$ but in most cases there have been small sample sizes or short periods of observation. For this reason we have undertaken a follow up study of our 10 year experience of percutaneous mitral commissurotomy.

\section{Methods}

From February 1986 to February 1996, 532 patients underwent percutaneous balloon mitral commissurotomy by trans-septal approach in our institution. The double balloon technique was used in the first 161 patients and the Inoue balloon in the remaining 371. Clinical, echocardiographic, and haemodynamic data were analysed retrospectively.

Cross sectional echocardiography and Doppler colour flow imaging were performed in all patients one or two days before commissurotomy and within 48 hours afterwards. Mitral valve anatomy was scored by cross sectional echocardiography and fluoroscopy on the basis of the three group classification proposed by Iung and co-worker ${ }^{23}$ - group 1: pliable non-calcified anterior mitral leaflet and mild subvalvar disease (thin chordae $\geqslant 10 \mathrm{~mm}$ long); group 2: pliable non-calcified anterior mitral leaflet and severe subvalvar disease (thickened chordae $<10 \mathrm{~mm}$ long); group 3: calcification of mitral valve of any extent, as assessed by fluoroscopy, whatever the state of the subvalvar apparatus. Commissural splitting and mitral valve area (planimetry) were assessed from the parasternal short axis view. Mean transmitral pressure gradient was determined from the continuous wave Doppler mitral velocity profile across the mitral valve in the apical four chamber view. Mitral regurgitation was detected and graded semiquantitatively with colour flow mapping in the parasternal long axis and apical four chamber view. 
Table 1 Preprocedure related variables in 532 patients

\begin{tabular}{|c|c|}
\hline Variable & Patients (n) \\
\hline \multicolumn{2}{|l|}{ Age (years) } \\
\hline$\leqslant 65$ & 435 \\
\hline$>65$ & 97 \\
\hline \multicolumn{2}{|c|}{ Body surface area $\left(\mathrm{m}^{2}\right)$} \\
\hline$\leqslant 1.8$ & 433 \\
\hline$>1.8$ & 99 \\
\hline Male/female & $108 / 424$ \\
\hline \multicolumn{2}{|c|}{ New York Heart Association functional class } \\
\hline$\leqslant$ II & 284 \\
\hline$>$ II & 248 \\
\hline \multicolumn{2}{|l|}{ Cardiac rhythm } \\
\hline Sinus & 294 \\
\hline Atrial fibrillation & 238 \\
\hline Previous surgical co & 96 \\
\hline \multicolumn{2}{|c|}{ Cardiothoracic ratio } \\
\hline$\leqslant 0.54$ & 341 \\
\hline$>0.54$ & 191 \\
\hline \multicolumn{2}{|l|}{ Echo score } \\
\hline 1 & 236 \\
\hline 2 & 220 \\
\hline 3 & 76 \\
\hline \multicolumn{2}{|c|}{ Mitral regurgitation (colour flow imaging) } \\
\hline No & 156 \\
\hline Yes & 376 \\
\hline \multicolumn{2}{|c|}{ Mitral valve area (planimetry) $\left(\mathrm{cm}^{2}\right)^{\star}$} \\
\hline$<1.0$ & 132 \\
\hline \multirow{2}{*}{\multicolumn{2}{|c|}{ Left atrial diameter (TM echo) (mm) }} \\
\hline & \\
\hline$\leqslant 55$ & 377 \\
\hline$>55$ & 155 \\
\hline \multicolumn{2}{|c|}{ Mean transmitral gradient (Doppler) $(\mathrm{mm} \mathrm{Hg})$} \\
\hline$\leqslant 10$ & 336 \\
\hline$>10$ & 196 \\
\hline \multicolumn{2}{|c|}{ Mitral valve area (haemodynamic) $\left(\mathrm{cm}^{2}\right)$} \\
\hline$<1.0$ & 171 \\
\hline$\geqslant 1.0$ & 361 \\
\hline \multicolumn{2}{|c|}{ Mean pulmonary artery pressure $(\mathrm{mm} \mathrm{Hg})$} \\
\hline$<25$ & 291 \\
\hline$\geqslant 25$ & 241 \\
\hline \multicolumn{2}{|c|}{ Mean left atrial pressure $(\mathrm{mm} \mathrm{Hg})$} \\
\hline$<20$ & 379 \\
\hline$\geqslant 20$ & 153 \\
\hline \multicolumn{2}{|l|}{ Balloon } \\
\hline Double balloon & 161 \\
\hline Inoue balloon & 371 \\
\hline
\end{tabular}

*Available in 408 of 532 patients.

PMC, percutaneous mitral commissurotomy.

FOLLOW UP

Follow up data were obtained either during hospital admission or readmission, or during patient visits to the outpatient department, or from a standardised questionnaire sent to patients and their attending physicians and cardiologists. On data collection, particular emphasis was placed on clinical and echocardiographic variables as potential predictive factors of long term outcome after commissurotomy. The clinical variables considered were age, sex, atrial fibrillation, cardiothoracic ratio, New York Heart Association (NYHA) functional class, and history of previous surgical commissurotomy or mitral commissurotomy. The cross sectional echocardiographic variables considered were mitral valve anatomy (echo score grade 1 was classed as anatomically favourable, echo score grade 2 as intermediate, and echo score grade 3 as unfavourable), left atrial diameter, mean transmitral gradient, mitral valve area assessed by planimetry, and severity of mitral regurgitation before and after mitral commissurotomy. The haemodynamic variables considered were: mean left atrial and pulmonary artery pressures, mitral valve area (Gorlin method), absolute gain in mitral valve area, and severity of mitral regurgitation before and after commissurotomy. We also considered whether the type
Table 2 Postprocedure related variables in 532 patients

\begin{tabular}{|c|c|}
\hline Variable & Patients (n) \\
\hline \multicolumn{2}{|c|}{ Mitral regurgitation (colour flow imaging) } \\
\hline$\leqslant 1$ & 442 \\
\hline$>1$ & 90 \\
\hline \multicolumn{2}{|c|}{ Mitral valve area (planimetry) $\left(\mathrm{cm}^{2}\right) \dagger$} \\
\hline$\leqslant 1.7$ & 145 \\
\hline$>1.7$ & 249 \\
\hline \multicolumn{2}{|c|}{ Mean transmitral gradient (Doppler) $(\mathrm{mm} \mathrm{Hg})$} \\
\hline$\leqslant 6$ & 437 \\
\hline$>6$ & 95 \\
\hline \multicolumn{2}{|c|}{ Mitral regurgitation (angiography) ${ }^{\star}$} \\
\hline$\leqslant 1$ & 396 \\
\hline$>1$ & 68 \\
\hline \multicolumn{2}{|c|}{ Mitral valve area (haemodynamic) $\left(\mathrm{cm}^{2}\right)^{\star}$} \\
\hline$\leqslant 1.7$ & 146 \\
\hline$>1.7$ & 318 \\
\hline \multicolumn{2}{|c|}{ Mean pulmonary artery pressure $(\mathrm{mm} \mathrm{Hg})$} \\
\hline$\leqslant 20$ & 317 \\
\hline$>20$ & 215 \\
\hline \multicolumn{2}{|c|}{ Mean left atrial pressure $(\mathrm{mm} \mathrm{Hg})$} \\
\hline$\leqslant 15$ & 435 \\
\hline$>15$ & 97 \\
\hline \multicolumn{2}{|c|}{ Mean transmitral gradient (haemodynamic) } \\
\hline$\leqslant 7$ & 440 \\
\hline$>7$ & 92 \\
\hline \multicolumn{2}{|c|}{ Absolute change in mitral area (haemodynamic) $\left(\mathrm{cm}^{2}\right)$} \\
\hline$<0.7$ & 189 \\
\hline$\geqslant 0.7$ & 343 \\
\hline
\end{tabular}
planimetry available in 394 patients postprocedure.

of balloon used (Inoue or double balloon) had any effect on long term outcome.

\section{MAJOR EVENTS}

Major events were defined as death (cardiac or non-cardiac), the need for mitral valve surgery (open chest mitral commissurotomy or mitral valve replacement) or repeat commissurotomy, persistence of functional impairment (grade III or IV of the NYHA classification), and entry to or return to NYHA class III/IV after initial improvement.

\section{STATISTICAL ANALYSIS}

Survival curves were generated by the KaplanMeier method. ${ }^{35}$ Late follow up results were determined using a composite end point, defined as survival with no mitral valve replacement, repeat percutaneous mitral commissurotomy, entry to or return to NYHA functional class III/IV, and death from cardiac or non-cardiac cause. Results were censored at the time of any of these end points.

Survival analysis was based on all 532 patients. Sixteen preprocedure related variables (table 1) and nine postprocedure related variables (table 2) were evaluated by Cox proportional hazard regression to identify predictors of poor outcome after commissurotomy. For continuous variables, patients were categorised into clinically accepted groups, as indicated in tables 1 and 2 . Univariate analysis was performed using a log-rank test on the 25 preand postprocedure related variables. The hazard ratios from the Cox analysis were used as estimates of relative risk.

To obtain independent predictors of long term poor outcome, multiple Cox regression analysis was performed with significant explanatory variables from the univariate analysis. Variables were included in the models if the probability for inclusion was less than 0.10, using a stepwise procedure. A variable was removed if the associated probability exceeded 
Table 3 Major events on follow up

\begin{tabular}{ll}
\hline Events & Patients $(n)$ \\
\hline Total events & $168(31.5 \%)$ \\
Non-cardiovascular death & $13(2.4 \%)$ \\
Cardiovascular death & $21(3.9 \%)$ \\
Sudden death & 2 \\
MVR & 3 \\
Cardiac failure & 7 \\
Acute myocardial infarction & 4 \\
Cerebrovascular accident & 2 \\
Pulmonary embolism & 1 \\
Bleeding & 2 \\
MVR or re-PMC & $106(19.9 \%)$ \\
Return to NYHA class III or IV & $28(5.3 \%)$ \\
\hline
\end{tabular}

MVR, mitral valve replacement; re-PMC, repeat percutaneous mitral commissurotomy; NYHA, New York Heart Association.

0.15 . The $95 \%$ confidence interval for relative risk was derived from the natural algorithm of the coefficient \pm 1.96 times the standard error. The hypothesis of proportional hazards was verified according to the method of Moreau et $a l .^{36}$ Survival curves were generated by multivariate methods to correct for the effects of other covariates. ${ }^{37}$

Estimates of errors cited in the text are mean (SD)

Data were analysed using the BMDP statistical software package (University of California, Berkeley, California, 1990).

\section{Results}

The results include data collected for 532 patients. Sixty nine $(12.9 \%)$ were referred from abroad, mainly from northern Africa, 19 of whom were subsequently lost to follow up. Average age was 54 (13) years; 424 (79.7\%) were female, $108(20.3 \%)$ male; atrial fibrillation was present in $238(44.7 \%)$; average cardiothoracic ratio was $0.54(0.07)$; and 96 patients $(18 \%)$ had a history of previous surgical commissurotomy. Sixty nine $(12.9 \%)$ were in NYHA class I, $215(40.4 \%)$ in class II, 222 $(41.7 \%)$ in class III, and $26(5 \%)$ in class IV. Favourable anatomy was present in 236 patients $(44.4 \%)$ (echo score grade 1 ), intermediate anatomy in 220 (echo score grade 2), and unfavourable anatomy in 76 (echo score grade 3$)$.

\section{HAEMODYNAMICS}

Mitral valve area determined by planimetry was on average $1.04(0.25) \mathrm{cm}^{2}$ before the procedure and increased to $1.68(0.34) \mathrm{cm}^{2}$ after the procedure $(\mathrm{p}<0.01)$. The mean mitral gradient was 12.2 (4.4) $\mathrm{mm} \mathrm{Hg}$ before the procedure, and decreased to 4.9 (2.1) afterwards

Table 4 Factors predicting poor outcome after percutaneous mitral commissurotomy (univariate analysis)

\begin{tabular}{llll}
\hline & $R R$ & $95 \%$ CI & $p$ \\
\hline Atrial fibrillation & 1.64 & 1.41 to 1.9 & 0.001 \\
Age $>$ 65 years & 2.5 & 2.12 to 2.97 & $10^{-5}$ \\
Cardiothoracic ratio > 0.54 & 1.87 & 1.61 to 2.18 & $10^{-5}$ \\
LA diameter $>55 \mathrm{~mm}$ & 1.59 & 1.36 to 1.86 & 0.004 \\
Echo score $>1$ & 2.31 & 1.96 to 2.70 & $10^{-5}$ \\
MR post-PMC > 1+ (colour flow mapping) & 1.6 & 1.32 to 1.94 & 0.02 \\
Mean PA pressure post-PMC > 25 mm Hg & 2.08 & 1.77 to 2.44 & $10^{-5}$ \\
Mean LA pressure post-PMC $>15 \mathrm{~mm} \mathrm{Hg}$ & 2.46 & {$[2.07 ; 2.92]$} & $10^{-5}$ \\
Mean mitral gradient post PMC > $6 \mathrm{~mm} \mathrm{Hg}$ (Doppler) & 2.07 & 1.73 to 2.44 & 0.0001 \\
MVA post PMC (haemodynamic) $\leqslant 1.7 \mathrm{~cm}$ & 1.69 & 1.44 to 1.99 & 0.0009 \\
Gain in MVA < 0.7 cm (haemodynamic) & 1.56 & 1.34 to 1.82 & 0.0004 \\
\hline
\end{tabular}

CI, confidence interval; LA, left atrial; MR, mitral regurgitation; MVA, mitral valve area; PA, pulmonary arterial; PMC, percutaneous mitral commissurotomy; RR, relative risk. $(\mathrm{p}<0.01)$. On colour flow imaging, 527 of the 532 patients $(99 \%)$ had mitral regurgitation $\leqslant$ grade 1 and five $(1 \%)>$ grade 1 before the procedure. After the procedure, mitral regurgitation $\leqslant$ grade 1 was found in 442 patients $(83 \%)$, and $>$ grade 1 in $90(17 \%)$.

Mitral valve area calculated from the haemodynamic data was $1.10(0.3) \mathrm{cm}^{2}$ and increased to $2.0(0.4) \mathrm{cm}^{2}$ after the procedure. The transmitral gradient decreased from 12 (4) to 4.5 (2) $\mathrm{mm} \mathrm{Hg}, \mathrm{p}=0.01$; mean left atrial pressure from 18 (5) to 10.5 (5) $\mathrm{mm} \mathrm{Hg}, \mathrm{p}=$ 0.01 ; and mean pulmonary artery pressure from 26 (4) to 20 (2) $\mathrm{mm} \mathrm{Hg}, \mathrm{p}=0.01$. Mitral regurgitation grade $1+$ was present in 158 patients before commissurotomy. After the procedure, 396 patients had grade 1 mitral regurgitation, 47 had grade 2 regurgitation, and 21 had grade 3 regurgitation or more.

EARLY RESULTS OF COMMISSUROTOMY

The success rate, defined as mitral valve area $\geqslant 1.5 \mathrm{~cm}^{2}$ and mitral valve regurgitation $\leqslant 2+$ at the end of the procedure, without major adverse clinical events, was $77 \%$ (410) in the whole cohort. The procedure was unsuccessful in 122 patients $(23 \%)$. Failure of the procedure was related to hospital death from retroperitoneal bleeding complicated by sepsis in one patient; incomplete procedure in 12 patients (failure to puncture septum in one, failure to cross the mitral valve or to stabilise the balloon on the mitral valve in three, haemopericardium requiring urgent surgical or non-surgical drainage in six, air embolism in the coronary artery system due to balloon rupture complicated by severe ventricular arrhythmias in two); occurrence of massive mitral regurgitation grade 3+ or more (21 patients), requiring emergency surgery in three, treated electively by mitral valve replacement without operative death in 13, or not operated on because of good haemodynamic and clinical tolerance in three, or refusal of operation in two cases; and insufficient valve opening in 88 patients.

\section{FOLLOW UP}

Mean follow up was 3.8 (4.0) years. Survival rate in the whole population was $94 \%, 91 \%$, and $83 \%$ at 3, 5, and 7.5 years, and event-free survival rate was $84 \%, 74 \%$, and $52 \%$ at the same time intervals. Events occurring on follow up are shown in table 3 . The total number of predefined events that occurred was 168 $(31.5 \%)$. Twenty one patients $(3.9 \%)$ died during follow up from cardiovascular related causes (sudden death in two, mitral valve replacement in three, cardiac failure in seven, acute myocardial infarction in three, cerebral vascular accident in three, pulmonary embolism in one, and bleeding complications in two); 13 patients $(2.4 \%)$ died of non-cardiac related causes (intracranial haemorrhage in two, cancer in eight, tuberculosis in one, cirrhosis of the liver in one, and following surgery on the gastrointestinal tract in one). Twenty eight patients $(5.3 \%)$ returned to (or entered) NYHA functional class III or IV after initial improvement (no echographic data available), and 106 (19.9\%) underwent mitral 
Table 5 Factors predicting poor outcome after percutaneous mitral commissurotomy (multivariate analysis)

\begin{tabular}{llll}
\hline & $R R$ & $95 \% C I$ & $p$ \\
\hline Echo score 3 & 2.58 & 2.19 to 3.05 & $10^{-5}$ \\
Echo score 2 & 1.87 & 1.59 to 2.16 & 0.004 \\
Age $>$ 65 years & 1.71 & 1.43 to 2.05 & 0.004 \\
Cardiothoracic index $>$ 0.54 & 1.37 & 1.17 to 1.62 & 0.05 \\
Mean transmitral gradient post-PMC $>$ 6 mm Hg (Doppler) & 1.80 & 1.52 to 2.14 & 0.001 \\
Mean pulmonary artery pressure post-PMC > 25 mm Hg & 1.58 & 1.34 to 1.88 & 0.007 \\
\hline
\end{tabular}

CI, confidence interval; PMC, percutaneous mitral commissurotomy; RR, relative risk.

Table 6 Event-free survival in selected subgroups of patients

\begin{tabular}{llll}
\hline & \multicolumn{3}{l}{ Event-free survival (\%) } \\
\cline { 2 - 3 } Predictive variable & 3 years & 5 years & 7.5 years \\
\hline Survival & 94 & 91 & 83 \\
Event-free survival & 84 & 74 & 52 \\
Echo score 1 & 92 & 84 & 70 \\
Echo score 2 & 86 & 73 & 34 \\
Echo score 3 & 45 & 25 & 16 \\
Age $\leqslant$ 65 years & 80 & 70 & 45 \\
Age $>$ 65 years & 52 & 38 & 17 \\
Cardiothoracic index $\leqslant 0.54$ & 82 & 70 & 51 \\
Cardiothoracic index $>0.54$ & 64 & 54 & 25 \\
MPAM postprocedure $\leqslant 25 \mathrm{~mm} \mathrm{Hg}$ & 81 & 70 & 43 \\
MPAM postprocedure $>25 \mathrm{~mm} \mathrm{Hg}$ & 67 & 56 & 35 \\
Mean transmitral gradient post-PMC $\leqslant 6 \mathrm{~mm} \mathrm{Hg}$ (Doppler) & 79 & 68 & 45 \\
Mean transmitral gradient post-PMC $>6 \mathrm{~mm} \mathrm{Hg}$ (Doppler) & 56 & 49 & 23 \\
\end{tabular}

MPAM, mean pulmonary artery pressure; PMC, percutaneous mitral commissurotomy.

valve replacement or repeat mitral commissurotomy-necessitated by a failed or unsuccessful procedure in 59 patients within days or weeks after the procedure, by progression of mitral regurgitation in two patients, by echographic restenosis in 18 patients, and by functional deterioration after initial improvement with no apparent anatomical reason in 27 patients.

FACTORS PREDICTING POOR OUTCOME AFTER COMMISSUROTOMY

Eleven clinical and echocardiographic variables predictive of late adverse outcome were identified by univariate analysis. These included five preprocedure variables and six postprocedure variables. Preprocedure variables were atrial fibrillation, age $>65$ years, cardiothoracic ratio $>0.54$, left atrial diameter $>55 \mathrm{~mm}$, and echo score. The postprocedure variables were all related to the immediate haemodynamic effects of the commissurotomy-mitral regurgitation (colour flow mapping) $\geqslant 1+$, mean pulmonary artery pressure $>20 \mathrm{~mm} \mathrm{Hg}$, mean left atrial

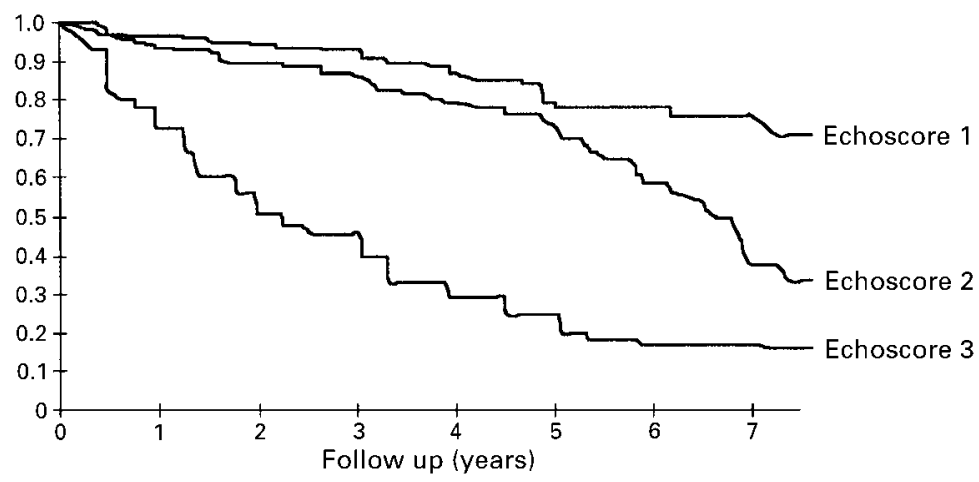

Figure 1 Multivariate adjusted survival curves showing the probability of event-free survival according to the echo score before percutaneous mitral commissurotomy, after adjustment for other covariates. pressure $>15 \mathrm{~mm} \mathrm{Hg}$, pressure gradient (Doppler) $>6 \mathrm{~mm} \mathrm{Hg}$, mitral valve area (haemodynamic) $\leqslant 1.7 \mathrm{~cm}^{2}$, and gain in mitral valve area $<0.7 \mathrm{~cm}^{2}$ (table 4 ).

Five independent predictors of late adverse outcome were identified by multivariate analysis - three clinical preprocedure variables (echo score, age, cardiothoracic ratio) and two postprocedure variables related to the quality of the results of the procedure (mean pulmonary artery pressure and mean transmitral gradient $>6 \mathrm{~mm} \mathrm{Hg}$ (table 5)). The values for event-free survival at 3,5 , and 7.5 years after the procedure, according to the five independent long term predictors, are given in table 6 . The event-free survival according to echo score was particularly interesting (fig 1). Event-free survival was $83 \%, 72 \%$, and $63 \%$ at 3,5 , and 7.5 years in patients with an echo score of 1 ; $86 \%, 73 \%$, and $34 \%$ in those with an echo score of 2 ; and $45 \%, 25 \%$, and $16 \%$ in those with an echo score of 3 at the same time intervals. In the subgroups of patients with echo scores of 2 and 3 , the same three independent predictors of poor long term outcome were identified: age $>65$ years, NYHA class grade II, and mean mitral gradient after commissurotomy of $>6 \mathrm{~mm} \mathrm{Hg}$.

\section{Discussion}

The aim of our study was to determine the predictors of long term outcome after percutaneous mitral commissurotomy. The composite end point adopted in our study took into account cardiac and non-cardiac death, repeat mitral commissurotomy or surgery, and lack of functional improvement or functional deterioration (that is, return to NYHA class III or IV).

LONG TERM FUNCTIONAL OUTCOME

Our study reports a 10 year experience of percutaneous mitral commissurotomy carried out in a single centre from February 1986 to February 1996. The average age of the patients in this series was relatively high compared with other series. The vast majority of the population was white, and only $69(12.9 \%)$ of the patients were referred from abroad. Only 19 patients were lost to follow up, so homogeneous follow up data were available for $96.4 \%$ of patients. Our results confirm the acknowledged efficacy of percutaneous mitral commissurotomy in terms of survival and event-free survival. With somewhat different average ages and inclusion criteria, event-free survival was found to be $51 \%$ at five years by Cohen et al and $65 \%$ by Orrange et al, ${ }^{26}{ }^{34}$ both groups reporting series of patients in the older age range, and $76 \%$ by Iung et al, who only considered patients with a good initial result. ${ }^{33}$ Few data have so far been reported after five years. Orrange et al, with a smaller series of 132 patients, found that 7 year and 5 year event-free survival figures were similar. ${ }^{34}$ Ben Farhat et al reported excellent 7 year event-free survival $(>80 \%)$, but in 30 highly selected patients with favourable anatomy. ${ }^{19}$ In our study, on the other hand, functional results deteriorated after five years, event-free survival rate being as low as $52 \%$ at 7.5 years. Late 
functional deterioration was previously shown to be related to various factors: occurrence of rhythm disturbances such as permanent atrial fibrillation, progression of coexisting valvar disease or concomitant non-valvar disease, or coexisting obstructive pulmonary disease, and restenosis - shown in previous reports to vary from 0 to $51 \%$ after 7.5 to 24 months following percutaneous or surgical closed chest commissurotomy. ${ }^{13} 15181927283032$

\section{PREDICTORS OF LONG TERM OUTCOME}

Echocardiographic score, describing valve deformity, was found to be the most powerful independent predictor of long term functional result. The best results were observed in patients with most favourable anatomy, eventfree survival at 7.5 years being as high as $70 \%$ in this group. The long term outcome of patients with intermediate anatomical form was almost as good as that of patients with favourable anatomy up to 5 years, but after 5 years the two event-free survival curves started to diverge. In patients with less favourable anatomy, functional outcome was particularly bad, falling as low as $45 \%$ at 3 years, and $16 \%$ at 7 years. In this category of patients, the curves started diverging within the first year; this indicates that most of the suboptimal results probably occurred in this subgroup, where there is a poor functional outcome after a few months or years. Our findings are in agreement with previous reports in which valve anatomy, assessed either by mitral valve echocardiographic score or by grading of fluoroscopic calcification, was identified as a strong predictor of long term and sometimes immediate results. ${ }^{19} 20262931353839$ The other interesting finding of this study was that age and cardiothoracic ratio were also important predictors of long term functional outcome.

Postprocedure variables reflecting the quality of the procedure - that is, mean mitral gradient and residual pressure in pulmonary circulation-were also found to be independent predictors. Similar observations have been made by Palacios et $a l,{ }^{29}$ Iung et $a l l^{33}$ and Orrange $e t a l l^{34}$ who identified postprocedure mitral valve area as a good predictor of long term functional outcome. Cohen et $a l$ and Dean et al both identified increased left ventricular end diastolic pressure, indicating that depressed left ventricular function, possibly induced by comorbidity, may also influence functional results. ${ }^{26}{ }^{31}$ Pulmonary artery systolic pressure was found to be predictive by Dean et al. ${ }^{31}$ The presence of moderate mitral regurgitation was associated with poor long term outcome in a study by Alfonso et al. ${ }^{40}$

Overall, it appears that there are useful prognostic indicators that should be recorded before mitral valve commissurotomy is undertaken, and of these the echo score is the most informative. The scoring system used in our study is based on a very clear definition of the anatomical form, taking into account the thickness and pliability of the valves, the length of the chordae, the degree of involvement of the subvalvar apparatus, and the presence or absence of calcifications on fluoroscopy. ${ }^{23}$ This scoring system is easier to use in daily routine practice than other systems that are based on more complicated assessment of several variables. $^{20}$

CLINICAL IMPLICATIONS

Our results show that the great majority of patients with adequate or intermediate anatomical form had event-free survival for up to five years after percutaneous mitral commissurotomy, but that the functional outcome deteriorated after five years in those with intermediate anatomical form. In patients with unfavourable anatomy, deterioration of the functional result started immediately after the procedure, event-free survival being as low as $45 \%$ after three years. Greater age and NYHA functional class were also among the independent predictors of poor functional outcome in patients with less favourable anatomy (echo scores of 2 or 3 ). Based on these observations, mitral valvoplasty can be strongly recommended for patients with favourable or intermediate valve anatomy, since this guarantees good functional results for at least five years in this particular subset of patients. In patients with unfavourable anatomy, our data suggest that the indications for percutaneous mitral commissurotomy should be reconsidered, since there are unlikely to be satisfactory midterm results at five years postprocedure. In such cases, mitral valve replacement might be indicated after a short period of observation. Postponement of mitral valve replacement in elderly people may result in them coming to surgery in a worse physical condition than at the initial screening, because of functional deterioration after a commissurotomy. Mitral valve replacement as a primary procedure in this subset of patients also makes economic sense, since the cost of balloon mitral commissurotomy, although not prohibitive, needs to be added to the cost of mitral valve replacement a few years later.

We are indebted to Sophie Boucher and Fiona Caulfield for their help in writing this paper.

1 Inoue K, Owaki T, Nakamura T, et al. Clinical application of ransvenous mitral commissurotomy by a new balloon catheter. F Thorac Cardiovasc Surg 1984;87:394-402.

2 Lock JE, Khalilullah M, Shrivastava S, et al. Percutaneous catheter commissurotomy in rheumatic mitral stenosis. $N$ Engl f Med 1985;313:1515-18.

3 Al Zaibag M, Al Kassab S, Ribeiro PA, et al. Percutaneous double balloon mitral valvotomy for rheumatic mitral

4 Babic UU, Pejcic P, Djurisic Z, et al. Percutaneous transarterial balloon valvuloplasty for mitral stenosis. Am $\mathcal{F}$ Cardiol 1986;57:1101-4.

5 Vahanian A, Slama M, Cormier B, et al. Valvuloplastie mitrale percutanée chez l'adulte. Arch Mal Coeur 1986;79: rale percutane

6 Palacios IF, Block PC, Brandi S, et al. Percutaneous balloon valvotomy for patients with severe mitral stenosis. Circulation 1987;75:778-84.

7 Vahanian A, Miche PL, Cormier B, et al. Results of percutaneous mitral commissurotomy in 200 patients. Am $\mathcal{F}$ Cardiol 1989;63:847-52.

8 McKay RA, Lock JE, Safian RD, et al. Balloon dilatation of mitral stenosis in adult patients in postmortem and percutaneous mitral valvuloplasty studies. F Am Coll Cardiol 1987;9:723-31.

9 Bassand JP, Schiele F, Bernard Y, et al. The double-balloon and Inoue techniques in percutaneous mitral valvuloplasty: comparative results in series of 232 cases. $7 \mathrm{Am}$ Coll Cardiol 1991;18:982-9.

10 Al Zaibag M, Riberio PA, Al Kasab S, et al. One-year follow-up after percutaneous double balloon mitral valvotomy. Am f Cardiol 1989;63:126-7. 
11 Nobuyoshi M, Hamasaki N, Kimura T, et al. Indications, complications and short-term clinical outcome of percutaneous transven

12 The National Heart, Lung and Blood Institute Balloon Valvuloplasty Registry Participants. Multicenter experience with balloon mitral commissurotomy. NHLBI Balloon Valvuloplasty Registry Report on immediate and 30-day follow-up results. Circulation 1992;85:448-61.

13 Palacios IF, Block PC, Wilkins GT, et al. Follow-up of patients undergoing percutaneous mitral balloon valvotomy. Analysis of factors determining restenosis. Circulation 1989;79:573-9.

14 Hung JS, Chern MS, Wu JJ, et al. Short and long-term results of catheter balloon percutaneous transvenous mitral commissurotomy. Am 7 Cardiol 1991;67:854-62.

15 Desideri A, Vanderperren O, Serra A, et al. Long term (9-33 months) echocardiographic follow-up after successful per-
cutaneous mitral commissurotomy. Am f Cardiol 1992;69: 1602-6.

16 Block PC, Palacios IF, Jacobs ML, et al. Mechanism of percutaneous balloon valvotomy. Am f Cardiol 1987;59:178-9.

17 Reyes VP, Raju BS, Wynne J, et al. Percutaneous balloon valvuloplasty compared with open surgical commissurotomy for mitral stenosis. N Engl f Med 1994;331:9617.

18 Arora R, Nair M, Kalra GS, et al. Immediate and long-term results of balloon and surgical closed mitral valvulotomy: a randomized comparative study. Am Heart $\mathcal{F}$ 1993;125: 1091-4.

19 Ben Farhat M, Ayari M, Maatouk F, et al. Percutaneous balloon versus surgical closed and open mitral commissurotomy. Seven year follow-up results of a randomized trial. Circulation 1998;97:245-50

20 Wilkins GT, Weyman AE, Abascal VM, et al. Percutaneous balloon dilatation of the mitral valve-an analysis of echocardiographic variables related to outcome and the mechanism of dilatation. Br Heart $\mathcal{F}$ 1988;60:299-308

21 Cormier B, Vahanian A, Michel PL, et al. Evaluation par échocardiographie bidimensionnelle et Doppler des reechocardiographie bidimensionnelle et Doppler des resultats de la valvulopla

22 Reid CL, Chandraratna PAN, Kawanishi DT, et al. Influence of mitral valve morphology on double-balloon catheter valvuloplasty in patients with mitral stenosis: analysis of factors predicting immediate and 3-month results. Circulation 1989;80:515-24.

23 Iung B, Cormier B, Ducimetiere P, et al. Immediate results of percutaneous mitral commissurotomy. A predictive model on a series of 1514 patients. Circulation 1996;94: 2124-30.

24 Block PC, Palacios IF, Block EH, et al. Late (two-year) follow-up after percutaneous balloon mitral valvotomy. $A m$ f Cardiol 1992;69:537-41.

25 Chen CR, Cheng TO, Chen JY, et al. Long-term results of percutaneous mitral valvuloplasty with the Inoue balloon catheter. Am f Cardiol 1992;70:1445-8.
26 Cohen DJ, Kuntz RE, Gordon SP, et al. Predictors of longterm outcome after percutaneous balloon mitral valvuloplasty. N Engl f Med 1992;327:1329-35.

27 Chan CN, Berland J, Cribier A, et al. Results of percutaneous transseptal mitral commissurotomy in patients 40 years and above with those under 40 years of age: immediate and 5-year follow-up results. Cathet Cardiovasc Diagn 1994;32: 223-30.

28 Ruiz CE, Zhang HP, Gamra H, et al. Late clinical and echocardiographic follow-up after percutaneous balloon dilatation of the mitral valve. Br Heart f 1994;71:454-8.

29 Palacios IF, Tuzcu ME, Weyman AE, et al. Clinical follow-up of patients undergoing percutaneous mitral balloon valvotomy. Circulation 1995;91:671-6.

30 Zhang HP, Gamra H, Allen JW, et al. Comparison of late outcome between Inoue balloon and double-balloon techniques for percutaneous mitral valvotomy in a matched study. Am Heart f 1995;130:340-4.

31 Dean LS, Mickel M, Bonan R, et al. Four-year follow-up of patients undergoing percutaneous balloon mitral commissurotomy: a report from the National Heart, Lung, and Blood Institute Balloon Valvuloplasty Registry. $\mathcal{F} \mathrm{Am}$ Coll Cardiol 1996;28:1452-7.

32 Trevino AJ, Ibarra $M$, Garcia A, et al. Immediate and long-term results of balloon mitral commissurotomy for rheumatic mitral stenosis: comparison between Inoue and double-balloon techniques. Am Heart ff 1996;131: 530-6.

33 Iung B, Cormier B, Ducimetiere P, et al. Functional results 5 years after successful percutaneous mitral commissurotomy in a series of 528 patients and analysis of predictive factors. $\mathcal{F}$ Am Coll Cardiol 1996;27:407-14.

34 Orrange SE, Kawanishi DT, Lopez BM, et al. Actuarial outcome after catheter balloon commissurotomy in patients with mitral stenosis. Circulation 1997;95:382-9.

35 Kaplan EL, Meier P. Non parametric estimation from incomplete observations. F Am Stat Assoc 1958;53:457-81.

36 Moreau T, O'Quigley J, Mesbah M. A global goodness of fit statistics for the proportional hazards model. Appl Stat 1985;34:212-18.

37 Lee ET. Statistical methods for survival data analysis. New York: John Wiley and Sons, 1992.

38 Pan M, Medina A, Suarez de Lezo J, et al. Factors determining late success after mitral balloon valvulotomy. Am 7 Cardiol 1993;71:1181-5.

39 Zhang HP, Allen JW, Lau FY, et al. Immediate and late outcome of percutaneous balloon mitral valvotomy in patients with significantly calcified valves. Am Heart f 1995;129: 501-6.

40 Alfonso F, Macaya C, Hernandez R, et al. Early and late results of percutaneous mitral valvuloplasty for mitral stenosis associated with mild mitral regurgitation. $A m \mathcal{F}$ Cardiol 1993;71:1304-10. 